\title{
En memoria de ellos La actualidad de un cristianismo liberador
}

\author{
F. Javier Vitoria Cormenzana, \\ Universidad de Deusto, Bilbao, \\ Cristianisme i Justícia, Barcelona, \\ Centro de Reflexión Teológica, San Salvador.
}

El pasado tres de marzo el diario El País entrevistaba a Noam Chomsky, eminente lingüista y activista político, auténtico azote de la política exterior norteamericana desde hace décadas. Reproduzco las dos últimas preguntas de la periodista y sus respuestas.

" $P$. Acaba de cumplir 80 años. ¿Qué le hace seguir luchando? R. Imágenes como ésa. [Chomsky indica un cuadro que cuelga de su despacho en el que se ve al ángel exterminador junto al cardenal Romero y seis intelectuales jesuitas asesinados en El Salvador en los ochenta por los escuadrones de la muerte]. Uno de mis fracasos es que ningún estadounidense sepa qué significa ese cuadro. $P$. ¿Se ha sentido alguna vez como un Don Quijote? R. No, porque los molinos son reales y algunos incluso los hemos abatido".

El veinticuatro de este mismo mes de marzo se han cumplido veintinueve años del asesinato del arzobispo Óscar Arnulfo Romero, y el próximo dieciséis de noviembre se cumplirán veinte del asesinato de Ignacio Ellacuría y de sus cinco compañeros, Ignacio Martín-Baró, Segundo Montes, Joaquín López y López, Amando López y Juan Ramón Moreno, así como Elba Julia Ramos, que trabajaba en la comunidad de los jesuitas, y su hija Celina. Todos ellos habían entregado sus vidas a la lucha, de una manera u otra, contra "el molino real" de la injusticia y al servicio de su víctima: el pueblo crucificado. Todos ellos fueron abatidos mortalmente por "el ángel exterminador" que siempre acompaña a la realidad homicida de la pobreza y de la opresión. Todos ellos fueron márti- 
res. "Mártires jesuánicos" los ha llamado Jon Sobrino ${ }^{1}$ porque actualizaron en El Salvador - "historizaron"— la vida, la muerte y la resurrección de Jesús de Nazaret. Con todos ellos Dios pasó por El Salvador.

Sería un fracaso para la Iglesia y para la teología que acabemos por no saber qué significa el cuadro de Chomsky. Y hablo del significado y no simplemente de los "facta bruta" que ocurrieron en aquel país centroamericano. Las balas asesinas pudieron arrancarles la vida, pero no el sentido con el que ellos quisieron vivirla. Como nos recuerda Roberto Casas en un texto sobre la teología salvadoreña a punto de publicarse ${ }^{2}$, a estos mártires "jesuánicos" "lo que verdaderamente les da sentido no es su propia vida eximia, sino aquellos por los cuales entregaron su vida, el pueblo crucificado, el "pueblo martirial”." ¿QQué es lo que da sentido a qué?", se pregunta. Y responde: "el pueblo crucificado es, en definitiva, lo que da sentido a los mártires jesuánicos". Y como un desafío para nosotros, los cristianos y los teólogos, añade: "No hay que olvidar que son esos mártires jesuánicos los primeros que nos piden que no nos centremos en ellos, sino en el pueblo crucificado".

¿Cómo olvidar al pueblo crucificado salvadoreño y seguir siendo seguidor de Jesús de Nazaret? ¿Cómo poder olvidar con él a tantos y tantos pueblos de esta aldea global condenados a vivir permanentemente en corredores de muerte y seguir haciendo teología en memoria del Crucificado? A las pocas horas de la histórica victoria electoral del FMLN (Frente Farabundo Martí para la Liberación Nacional), Rodolfo Cardenal, un observador excepcional del país salvadoreño, escribía en El Periódico de Barcelona, dando algunas noticias del vía crucis del pueblo salvadoreño en tiempos de "paz": "Estas novedades [la alternancia en el poder y la llegada a la Presidencia de la República del FMLN, la ex guerrilla] se explican por el profundo descontento generado por dos décadas de gobiernos neoliberales, que no cumplieron con la promesa de generar prosperidad y que menospreciaron a los movimientos sociales y su poder para cambiar el Gobierno con su voto. El vaso de la prosperidad nunca se derramó. Al contrario, la riqueza se concentró cada vez más, con lo cual creó una de las desigualdades latinoamericanas más grandes, empujó a las reducidas clases medias hacia la línea de la pobreza y desató una de las corrientes migratorias más nutridas de Centroamérica. En efecto, aproximadamente un tercio de la población salvadoreña vive hoy en el norte, sobre todo en Estados Unidos. Los gobiernos neoliberales intensificaron la expulsión de salvadoreños, al mismo tiempo que las remesas de los emigrantes experimentaron tal crecimiento que han mantenido a flote a la economía nacional durante estos años. Mientras tanto, la inseguridad se ge-

1. "Los mártires jesuánicos en el Tercer Mundo", Revista Latinoamericana de Teología 48 (1999) 237-255.

2. Dios pasó por El Salvador. La relevancia teológica de las tradiciones narrativas de los mártires salvadoreños, IDTP/Desclée de Brouwer, Bilbao, 2009. 
neralizó tanto que El Salvador figura hoy en los primeros puestos de la lista de países más violentos del mundo. Uno de los fenómenos más desconcertantes de la violencia social que asuela al país lo constituyen las pandillas juveniles, conocidas como maras. La inadecuada política gubernamental permitió que estas se volvieran letales al asociarse con el narcotráfico y el crimen organizado. En buena medida, pues, la derrota del partido de gobierno, vinculado primero a los escuadrones de la muerte y luego a los escuadrones de limpieza social, al asesinato de monseñor Romero y de los jesuitas de la UCA, representa el repudio de la población salvadoreña a un régimen neoliberal sin concesiones".

Mantener viva la memoria de aquello que dio sentido a la vida de los mártires nos permite no olvidar que "al fin y al cabo lo más notable del cristianismo está en que en su nombre no es lícito vender por un plato de lentejas no solo lo santo, pero ni siquiera el mundo con su historia de sufrimiento"3. No me parece que esto sea hoy obvio. Ni en el primero, ni en el tercero de los mundos. Al menos, entre quienes dedicamos nuestras vidas a la teología o entre quienes dirigen pastoralmente al Pueblo de Dios. Cada vez que he vivido en El Salvador se ha hecho más verdad para mí "la permanente tentación gnóstica del cristianismo"4. No es el momento de explicar en qué consistió el polifacético fenómeno gnóstico de la antigüedad. Ni de entrar en las relaciones actuales entre gnosis y praxis política. Pero sí de recordar que en tiempos de crisis de Dios, como los que vivimos, la gnosis se convierte en tentación: Dios y el mundo, Dios y la historia ya no pueden pensarse conjuntamente. Es tentación no solo para los ateos o los agnósticos, sino también para los católicos. No solo en Europa, sino también en el Tercer Mundo. Los mártires, y muy singularmente I. Ellacuría, hicieron exactamente lo contrario: "historizar" la salvación de Dios, hacerse cargo, encargarse de y cargar conjuntamente con Dios y la historia crucificada del pueblo al que sirvieron. El precio de tal atrevimiento lo pagaron con su propia vida. Pero su memoria viva es un reparo permanente a la aguda psicologización de los procesos vitales en la que nos encontramos inmersos. Las únicas relaciones humanas que parecen vivas y operativas son las que el individuo establece con su propio yo en busca de su auténtica identidad, del verdadero "sí mismo" que se encuentra en lo más recóndito de su ser y que fácilmente identifica con "lo divino". El gnóstico de ayer y el gnóstico de hoy, aunque no se reconozcan en este nombre, tienen en común que se consideran un ser autosuficiente y autorreferido en todos los órdenes de la existencia. La salvación es un asunto privado que solo le compete a él. El otro le parece innecesario y de su presencia no le brota ninguna responsabilidad hacia él. Y finalmente el tiempo histórico lo pone

3. J. B. Metz, La fe, en la historia y la sociedad, Cristiandad, Madrid, 1979, p. 129.

4. Cfr. íd., Memoria passionis. Una evocación provocadora en una sociedad pluralista, Sal Terrae, Santander, 2007, pp. 152-154. 
entre paréntesis porque es fuente de conflicto 5 . Justamente lo contrario de lo que nos recuerdan los mártires. Ellos vivieron empeñados en un proseguimiento de las huellas históricas del Dios compasivo y copartícipe de la condición humana: Jesús de Nazaret. Encontraron su rastro en el rostro del prójimo, es decir, en el pueblo crucificado al que se aproximaron para curar sus heridas y mitigar su dolor ( $c f r$. Lc 10, 29-37). Barruntaron la visita de Dios en los pequeños que sufren ( $c f r$. Mt 25, 40). Se experimentaron alimentados, saciados, hospedados, revestidos, visitados y mirados por Él, cada vez que practicaron y convirtieron en historia viva el principio misericordia ( $c f r$. Mt 25, 31 ss.). Y aunque también escucharon el silencio de Dios, se dejaron iluminar por su eclipse y se sintieron acompañados por su abandono en su solidaridad con el pueblo crucificado. En la itinerancia de su vida cristiana descubrieron que Dios les reclamaba la desposesión de sus propios intereses materiales y espirituales. La llave que le abrió a la experiencia del Dios del Reino no fue "el descubrimiento de quién soy yo en función de yo mismo", sino la edificación del "hombre interior" en función de las necesidades y demandas de quienes sufrían opresión e injusticia y a quienes, como consecuencia de su aproximación solidaria y misericordiosa, convirtieron paulatinamente en próximos y allegados hasta el punto de ser crucificados como ellos.

La memoria de los mártires refuerza la confianza en la vigencia de un cristianismo liberador en un mundo tan plagado de situaciones de miseria dramática como el nuestro y tan necesitado de un orden global alternativo. Sin embargo, no nos hacemos ilusiones acerca de su viabilidad histórica. Ni muchas, ni pocas. El panorama actual del catolicismo - y no solo del europeo — no da para casi ninguna.

\section{Una fe en lo irrenunciable sin ilusiones}

¿Por qué fe sí e ilusiones no? La "memoria passionis et resurrectionis" nos prohíbe identificar la esperanza cristiana con el optimismo histórico. Legítimamente podemos interpretar los sufrimientos del tiempo presente como dolores del parto de la creación nueva, y sus lamentos como los gemidos del Espíritu anhelante de Dios ( $c f r$. Rom 8, 18-25). Pero nadie nos asegura su feliz alumbramiento, ni la metamorfosis de las lágrimas en cantos de liberación. Tampoco el Dios que resucitó a Jesús crucificado. Su Presencia actuante y salvífica en la historia motiva, tensa, inquieta y moviliza constantemente los corazones de los seres humanos en la dirección de la liberación del Reino, pero sin violentar sus libertades. Su Espíritu impulsa permanentemente a la comunidad cristiana historia adentro y opera en la acción de los cristianos que se ponen "al servicio de sus hermanos y hermanas, en los puntos donde se juegan éstos su existencia y su porvenir" (Pablo VI). Como reclamara Alfonso Carlos Comín, Dios nos

5. Puede encontrarse un interesantísimo estudio sobre la gnosis antigua y actual en L. Duch, Un extraño en nuestra casa, Herder, Barcelona, 2007, pp. 273-357. 
"necesita" "fuera del templo y de los templos subsidiarios construidos por la institución”. Nuestra colaboración le resulta indispensable para enjugar lágrimas, mitigar sufrimientos y hacer realidad ese mundo nuevo que es la morada de Dios con los seres humanos (cfr. Ap 21, 3-5).

Pero esta pretensión divina de liberación y reconciliación no siempre se cumple en la historia. Por una parte, el barullo del día a día nos ciega a los cristianos para ver los signos del Espíritu y nos ensordece para oír su clamor en los gritos de los empobrecidos y en el lamento de nuestra alma desvalida ( $c f r$. Mc 8, 18). La libertad humana puede ser, sin duda, ciega y sorda a la llamada de Dios y, en este caso, su proyecto para la historia humana quedará frustrado, porque este proyecto necesita de nuestro concurso y Dios no ha previsto que pueda ser realizado al margen de nuestra libertad. Su proyecto, que no es otro que el de la fraternidad total entre los humanos, de reconciliación universal de hombres y mujeres, trasciende — en tanto que la perfecciona - la noción misma de justicia. Y su llamada nos llega preferentemente a través del rostro de los pobres, de las víctimas de la injusticia. Precisamente porque el proyecto de Dios para la historia es que esta realidad de injusticia desaparezca de manera definitiva, su escondida Presencia se manifiesta en el lamento de todos aquellos que primariamente cargan con aquella realidad y en la acción de quienes se encargan de hacerla desaparecer. Todos ellos nos recuerdan dialécticamente —en la negación de su negación - el proyecto de Dios. Consecuentemente cuando los miembros de la Iglesia somos ciegos y sordos a la llamada de Dios oculta/presente en la víctimas, la praxis eclesial, sea cual sea su pretensión, ni se dirigirá $a$, ni se concentrará en los procesos de liberación en favor de nuestro prójimo.

Por otra parte la acción del Aliento de Dios habitualmente se parece más al susurro de una brisa suave que al ímpetu de un huracán que agrieta montañas y quiebra rocas ( $c f r .1$ Re 19, 11-12), mientras que el poder del pecado, aunque definitivamente vencido, sigue siendo descomunal. Con frecuencia hace morder el polvo de la derrota al Espíritu de Dios en la historia y a su Salvación, aunque no consiga desalojarles de ella. Allí donde el espíritu humano creador suscita vida y libertad, solidaridad y liberación, fantasía creadora y proyectos utópicos de nueva humanidad, el Espíritu se encuentra en acción y fermentación dentro de esta historia humana encadenada por el pecado, la injusticia y la muerte. Pero igualmente, allí donde la globalización de las relaciones económicas condena a la muerte a millones de seres humanos y a la desaparición a muchas y variadas formas de vida, allí donde la afirmación ególatra de la propia libertad genera insensibilidad y apatía ante el sufrimiento ajeno, allí donde la idolatría del buen vivir deshumaniza a los seres humanos, en una palabra, allí donde el pecado gobierna nuestra libertad, el Espíritu, que llena el universo, guía el curso de los tiempos con admirable providencia y renueva la faz de la tierra ( $c f r$. GS $11 ; 26)$, sufre un proceso de humillación, ocultamiento y kénosis. 
En estas circunstancias, el cristianismo necesita recordar permanentemente que lo verdaderamente importante y decisivo no es ni su éxito ni su fracaso en las luchas concretas en favor de la justicia, sino el amor servicial en favor de la liberación del prójimo. Dicho de otra manera, desde una perspectiva cristiana el compromiso con la liberación es válido por sí mismo, no en función de su eficacia o de sus resultados. Y los cristianos creemos que, por muchos que sean los sacrificios y las derrotas, este compromiso es siempre fructífero: no hay acto de amor que caiga en saco roto de manera definitiva e irreversible. A esta praxis de liberación - y no a otra- Dios le ha prometido en Jesucristo su especial presencia, como prolongación de su acción creadora y salvadora. La muerte de Jesús en la cruz, su amor "infructuoso" simbolizado en ella, muestra que toda praxis dirigida a la liberación y a la reconciliación en favor del prójimo es válida en y por sí misma y no solo por el éxito que eventualmente alcance. La salvación/liberación, la tarea encomendada por Dios a la Iglesia y todavía pendiente de realizar en nuestra historia, tendrá siempre el estigma del fracaso, las marcas del sufrimiento y de la muerte, la traza identitaria de un amor impotente, que al mismo tiempo jamás se da por vencido. Justamente esta experiencia es la que permite a los creyentes captar que la salvación no está en nuestras manos prometeicas humanas y que, a pesar de ello, Dios concede un futuro a todos nuestros esfuerzos de liberación y reconciliación, que supera los límites de nuestra historia ${ }^{6}$.

\section{No hay cristianismo vivo fuera de la liberación}

En lo tocante a la praxis de liberación el cristianismo se enfrenta con una cuestión decisiva e irrenunciable para su propia identidad. No debería desecharla o menospreciarla, ni siquiera por las "lentejas" de su éxito pastoral y su relevancia pública. Invirtiendo el axioma de san Cipriano, creo poder afirmar que "extra salutem nullus christianismus". Más aún, y dejando a un lado el temor a ser acusado de reduccionismo soteriológico, me atrevo a afirmar que "fuera de la liberación no hay Iglesia".

El control ideológico ejercido por el tradicionalismo católico nos suele obligar a justificar el uso del término liberación a quienes lo utilizamos como expresión de la Salvación de Dios. En vano repetimos una y otra vez que entendemos la liberación de forma holística e integral. Son inútiles nuestras aclaraciones en el sentido de que solamente buscamos un nexo entre las liberaciones históricas y la redención escatológica. Continuamos bajo la sospecha. Hay en la Iglesia una doble vara de medir que da por supuesto que en el tradicionalismo no existe ningún riesgo de reduccionismo. La alternativa "vida futura"-"vida presente" separa lo que Dios en Jesucristo y su Espíritu ha unido de manera indivisible e

6. Cfr. E. Schillebeeckx, Cristo y los cristianos. Gracia y Liberación, Cristiandad, 1982, pp. 819-820. 
inconfundible para siempre. "Precisamente porque espero la 'resurrección de los muertos y la vida de un mundo futuro', he de oponerme aquí y ahora a los poderes de la muerte y de la destrucción y amar tanto esta vida que trate de liberarla con todas mis fuerzas de la explotación, la opresión y la alienación. Y a la inversa: justamente porque amo la vida, me comprometo con su justicia y lucho por su libertad donde se encuentra amenazada, por eso espero que de una vez para siempre la muerte quede absorbida en la victoria de la vida y 'no haya ya más dolor, sufrimiento ni lamento' (Ap 21, 4s). Quien plantee el más acá y el más allá de la esperanza cristiana como una alternativa, roba a la esperanza cristiana tanto la fuerza para vivir como el consuelo en el morir"7.

Si no otorga liberación, el cristianismo vivido está paradójicamente muerto y a la Iglesia se le puede aplicar el calificativo de institución "zombi" (U. Beck). En realidad hablar de cristianismo liberador es una tautología. Un cristianismo vivo es aquel que libremente comunica salvación a hombres y mujeres libres. Obviamente también la liberación de la culpa y del pecado comprendido en clave profundamente teologal y no simplemente ética. ¿Cómo no reconocer la gran diferencia existente entre la liberación de las opresiones corporales psicosomáticas y sociopolíticas y la liberación del pecado y de la culpa? En el primer caso, los seres humanos podemos intervenir adecuadamente para poner remedio personal y socialmente; en el segundo, no hay intervención humana directa que pueda traer liberación. La respuesta cristiana al sufrimiento debido a la culpa es fruto de la gracia de Dios que "nos amó cuando aún éramos enemigos" (Rom 5, 10); es decir, dependemos totalmente de la gracia de Dios".

Estoy persuadido de que, tras la pérdida visible - ¿e irreversible? - de relevancia social del cristianismo en el nuevo orden globalizado, se esconde la pérdida de su relevancia salvífica. El cristianismo institucional ha perdido gran parte de su credibilidad como tradición que otorga salvación a la existencia humana. Aunque pueda parecer paradójico, el cristianismo está dejando de interesar como respuesta a la cuestión religiosa que es intrínsecamente la pregunta por la salvación. Un número creciente de hombres y mujeres se sienten cansados de escuchar discursos cristianos que nada significan para sus vidas, y están saturados de las doctrinas y los documentos solemnes del cristianismo. Buscan sedientos otras fuentes de aguas vivas y caminos nuevos de solidaridad, pues ya no encuentran en el cristianismo aquello que anhelan ver, tocar y sentir — quizás sin saberlo- acerca de la Palabra de Vida ( $c f r .1$ Jn 1, 1). Sin embargo, el Dios de Jesucristo sigue salvando en el mundo y en la historia y la Iglesia debería ser precisamente testigo de este poder salvador del Amor divino.

7. J. Moltmann, El Espíritu de la Vida, Sígueme, Salamanca, 1998, pp. 126-127.

8. Cfr. E. Schillebeeckx, óp. cit., p. 816. 


\section{3. ¿Qué significa una Iglesia como "pueblo mesiánico"?}

El Vaticano II recuperó definitivamente esta impronta mesiánica del cristianismo al introducir, a sugerencia de Y. Congar, en la Constitución dogmática sobre la Iglesia la expresión "pueblo mesiánico" (cfr. LG 9). Esta "vuelta a los orígenes" (cfr. Hech 11, 26) confirmó definitivamente el modelo histórico-salvífico de misión, inspirador del incipiente desarrollo del apostolado laical en la Iglesia de los primeros años del siglo XX. La Iglesia conciliar reconoce pública y solemnemente que su acción no es causa, garantía o condición de posibilidad de la misión salvífica de Dios, aunque ésta no se cumpla al margen de la historia de las libertades humanas. Ella cree en un Dios en misión permanente, se sabe fruto de su presencia salvífica en la historia y llamada por Él a ser signo e instrumento de la misión del Dios trinitario ( $c f r$. LG 2-4). Su misión en el mundo responde a la responsabilidad, contraída ante Dios y ante la sociedad, de animar la historia para que se mueva en la dirección que le señala el Espíritu del Dios de Jesucristo. El concilio propondrá la historia humana como el texto propio de la misión de la Iglesia (cfr. GS 34). Y, aunque reabre una nueva versión del viejo contencioso teológico sobre el natural/sobrenatural (desarrollo del Reino de Dios/progreso terreno, salvación escatológica/liberaciones humanas), contempla el servicio de los cristianos al perfeccionamiento del orden temporal como preparación del "material del reino de los cielos" ( $c f r$. GS 38) y como parte integrante de la misión de la Iglesia ( $c f r$. AA 5). Su meta escatológica de salvación sólo se podrá alcanzar plenamente más allá de la historia, pero avanza juntamente con toda la humanidad, experimenta la suerte terrena del mundo y encuentra su razón de ser en actuar como fermento y como alma de la sociedad que debe transformarse en familia de Dios ( $c f r$. GS 40). Creer en la vida eterna, más allá de la muerte, debería conducir a los cristianos, de manera inevitable, a luchar por la vida plena, más acá de la muerte. Por esto, la fe en el Reino es indistinguible del perfeccionamiento del orden temporal. La fe, como decía E. Mounier, nos arranca de la historia: nuestra salvación no está en nuestras manos, sino en las de Dios. Pero inmediatamente nos arroja de nuevo a ella violentamente: no podemos buscar a Dios al margen del mundo y de los hombres y de su proceso de humanización; el sacramento privilegiado de Dios es la experiencia de la fraternidad y ésta, lo queramos o no, es una experiencia radicalmente histórica, encarnada, terrenal.

Este modelo de misión, recibida en la conciencia eclesial, alcanza su formulación cumbre en la Evangelii nuntiandi de Pablo VI. La misión evangelizadora de la Iglesia no debe limitarse únicamente a la predicación del evangelio (cfr. n. 19). La conversión interior las personas, la transformación de los ambientes y de la realidad social, y la liberación de los hombres de todo aquello que les deshumaniza forma parte intrínseca de aquella misión. Evangelizar significa para la Iglesia "llevar la Buena Nueva a todos los ambientes de la humanidad y, con su influjo, transformar desde dentro, renovar a la misma humanidad"; su finalidad consiste en convertir, al mismo tiempo y por la sola fuerza divina del Evangelio, 
"la conciencia personal y colectiva de los hombres, la actividad en que ellos están comprometidos, su vida y ambientes concretos" ( $c f r$. n. 18). De forma coherente se resaltan los vínculos que unen profundamente la tarea evangelizadora y la promoción humana. Pasar por alto la importancia de los graves problemas que atañen a la justicia, a la liberación, al desarrollo y a la paz del mundo constituiría una grave tergiversación de la misión evangelizadora de la Iglesia (cfr. n. 31).

A diario el potencial liberador y humanizador del Evangelio de Dios ha de enfrentarse con la barbarie de la realidad y la historia del sufrimiento del mundo. Y esto convierte la participación en la transformación del mundo en una dimensión constitutiva de la misión de la Iglesia, que no es un fin en sí misma, sino un medio o instrumento sacramental al servicio de Dios y de su causa, la plena humanización/divinización del mundo. Si la vocación de la Iglesia es la redención del género humano y su liberación de toda situación opresiva, resulta inevitable para ella el compromiso con los procesos de transformación que pretenden desterrar el pecado estructural - esto es, el pecado objetivado en estructuras económicas, sociales, políticas o culturales - que produce el sufrimiento y la degradación que contradice el designio divino de humanización plena e integral para todos los hombres y las mujeres. El cristianismo en su conjunto ha adquirido el compromiso de hacer rentable lo recibido gratuitamente del Padre para el crecimiento del Reino ( $c f r$. Mt 25, 14-30). La fidelidad al mismo le llevará a descentrase de sí mismo y de su futuro para subordinarse al servicio de lo que Dios espera del mundo. Su praxis, crítica y liberadora, reclama hombres y mujeres pobres con espíritu; es decir, cristianos y cristianas de las bienaventuranzas?

\section{4. ¿Qué sacramentos para un cristianismo liberador?}

Todo lo que en el cristianismo empírico vaya contra o eluda las exigencias de liberación humana, individual y colectiva, debe ser rechazado o revisado en nombre de la fe cristiana. Esta normatividad afecta muy singularmente al modo como hoy celebramos los sacramentos cristianos. Me permito transcribir un texto que da mucho qué pensar sobre la praxis sacramental actual de la Iglesia e indirectamente denuncia las resistencias y perezas del tradicionalismo católico para revisarla:

"La convicción de que el sufrimiento humano no es algo necesario y la fe en que tal sufrimiento no puede ser definitivo y, por consiguiente, debe ser eliminado son vividos, simbólica y lúdicamente, en la liturgia cristiana. Los sacramentos son, de hecho, signos anticipadores y mediadores de la salvación, es decir, de una vida salvada y reconciliada. Y, dada nuestra situación histórica, son también símbolos de la protesta dirigida a desenmascarar una vida precaria, aún

9. Cfr. Y. Congar, Un pueblo mesiánico. La Iglesia, Sacramento de salvación, Cristiandad, Madrid, 1976, pp. 115-117. 
no reconciliada en la dimensión concreta de nuestra historia. Por ser una visión profética del Shalom universal, la liturgia tiene esencialmente una dimensión crítica. Mientras perdure entre nosotros la historia del sufrimiento, no podemos prescindir de la liturgia sacramental; eliminarla o descuidarla significaría condenar al silencio la firme esperanza de una paz y una reconciliación universales. En efecto, mientras la salvación y la paz no sean hecho real, deberemos afirmar $\mathrm{y}$, sobre todo, alimentar y mantener viva esa esperanza, lo cual no es posible sino mediante símbolos anticipadores. Debido precisamente a eso, la liturgia cristiana se mueve entre los grandes símbolos de la muerte y la resurrección de Jesús. La cruz es el símbolo de la lucha hasta la muerte contra la alienación de nuestra historia de sufrimientos, la consecuencia del mensaje de un Dios volcado hacia la humanidad; y la resurrección de Jesús manifiesta que el sufrimiento no puede tener la última palabra. La praxis sacramental invita, pues, al cristiano a una acción liberadora en nuestro mundo. La anticipación litúrgica de una vida reconciliada en la libre comunicación de una 'comunidad de Cristo' no tendría sentido alguno si no contribuyese a realizar de hecho una praxis liberadora en nuestro mundo. La liturgia sacramental es, por tanto, el lugar adecuado para que los creyentes se den realmente cuenta de que existe una dolorosa ruptura entre su visión profética del reino de paz de un Dios volcado hacia la humanidad y la situación real en que viven los hombres, de que nuestro sufrimiento no es necesario y, por tanto, es modificable. De ahí que, si se celebra correctamente, la acción simbólica de los sacramentos cristianos contiene un enorme potencial histórico, capaz de integrar mística y política (aunque sea a través de formas profanas). Evocando la pasión de Jesús, convertida en victoria por Dios $-\mathrm{y}$ en promesa para todos nosotros-, los cristianos celebran en la liturgia su unión efectiva con Jesús y, en virtud de ella, la posibilidad de una liberación y reconciliación creativas en nuestra historia"10.

Esta reflexión de Schillebeeckx me parece del todo central en este momento de la historia de la Iglesia. Son muchos los lugares del mundo donde la liturgia sacramental está desconectada por completo de los contextos culturales en los que se celebra y de las historias de sufrimiento de quienes la celebran. Esta doble desconexión abandona la liturgia a un triste estado de falta casi completa de significatividad para aquellos a los que pretendidamente se dirige. La cita del teólogo holandés nos recuerda que la eucaristía debería ser el lugar donde, permítaseme la expresión, "repostar el combustible" necesario para proseguir nuestro trabajo por la liberación del mundo y de los hombres, es decir, su humanización/divinización. El momento para redescubrir la razón espiritual última de nuestras causas históricas. El espacio donde realimentarse para recuperar las fuerzas necesarias para reemprender nuestro esfuerzo a favor de la causa de Dios. ¿Cumple hoy la eucaristía con esta función en la mayoría de los casos?

10. E. Schillebeeckx, óp. cit., pp. 818-819. El énfasis es mío. 
¿Encontramos de manera habitual en la liturgia cristiana de hoy la integración de mística y política de que nos habla Schillebeeckx? ¿Dónde está el potencial histórico de los sacramentos cristianos? ¿Encontramos los cristianos en ellos, en la forma como se celebran hoy, la fuerza subversiva que debería empujarnos a un proceso de "liberación y reconciliación creativas en nuestra historia"? Cualquier respuesta generalizadora a estas preguntas será, por supuesto, injusta. Pero es innegable que en una mayoría de los casos la respuesta ha de ser simplemente negativa.

\section{5. "No hagáis de Dios una caricatura de vuestro miedo" (Pietro de Paoli)}

Tras la dificultad para un cristianismo liberador subyace permanentemente en el imaginario católico una representación desvaída del Dios revelado en Jesucristo. Comparto la idea de que la crisis de Dios es un rasgo distintivo de una época que mantiene, sin embargo, una actitud positiva ante las religiones ${ }^{11}$. En este sentido me parece acertada la estrategia misionera oficial de la Iglesia católica, en Europa y no solo en ella, centrada fundamentalmente en traer consigo nuevamente a Dios, que se ha convertido en "un extraño en nuestra propia casa”. La preocupación eclesial está más que justificada. Más aún, si tenemos en cuenta que la proclividad humana a la idolatría es enorme porque Dios es el nombre que damos a "aquello que preocupa últimamente al hombre" (P. Tillich). Queda, sin embargo, una cuestión mayor por dilucidar: si el Dios que se pretende hacer presente, unas veces en las sociedades secularizadas y en los Estados laicos y otras en medio del batiburrillo de las sectas, es el Dios cristiano, es decir, el Dios revelado $a$ y en Jesús de Nazaret o un remedo del mismo.

Nadie puede pretender "poseer" en exclusiva la verdadera imagen del Dios cristiano, que siempre es mayor que nuestras ideas sobre Él. Tampoco yo. Pero sí me gustaría participar respetuosa y empáticamente en el diálogo abierto por Joseph Ratzinger/Benedicto XVI en su meditación sobre Jesús de Nazaret. El Papa enmarca el evangelio de Cristo y la buena nueva del Reino de tal manera que pretende hacer un llamamiento a las sociedades seculares, cuyos miembros han perdido el sentido de la trascendencia y la esperanza de una relación con Dios. Se pregunta por el significado de lo que Jesús llama "Reino de Dios", que "es sumamente complejo y sólo aceptando todo el conjunto podemos acercarnos a su mensaje y dejarnos guiar por él"12. Tras realizar un recorrido por las diferentes perspectivas históricas del Reino (la eclesiocéntrica, la cristocéntrica y la teocéntrica), que no es nuevo en el magisterio papal ${ }^{13}$, se detiene en el reinocen-

11. Cfr. J. B. Metz, Memoria passionis, óp. cit., pp. 77-126.

12. J. Ratzinger/Benedicto XVI, Jesús de Nazaret. Primera parte. Desde el Bautismo a la Transfiguración, La Esfera de los Libros, Madrid, 2007, p. 87.

13. Un recorrido semejante realiza Juan Pablo II en su encíclica Redemptoris missio. En su n. 17 dice textualmente: "Hoy se habla mucho del Reino, pero no siempre en sintonía con el sentir de la Iglesia. En efecto, se dan concepciones de la salvación y de 
trismo para descalificarlo sin ningún paliativo. Se trata de una reinterpretación secularista del concepto de "reino", que da lugar a una nueva visión del cristianismo, de las religiones y de la historia en general, pretendiendo lograr así con esta profunda transformación que el mensaje de Jesús sea de nuevo aceptable. Según la perspectiva reinocéntrica, la centralidad del reino sería, al fin y al cabo, el corazón del mensaje de Jesús y la vía correcta para unir por fin las fuerzas positivas de la humanidad en su camino hacia el futuro del mundo. "Reino" significaría simplemente un mundo en el que reinan la paz, la justicia y la salvaguarda de la creación. No se trataría de otra cosa. Este "reino" debería ser considerado como el destino final de la historia. Según el Papa lo más importante y más grave de esta comprensión es que Dios desaparece y quien actúa ahora es solamente el hombre. La fe, las religiones, son utilizadas para fines políticos. Solamente cuenta la organización del mundo y la religión interesa solo en la medida en que puede ayudar a esto ${ }^{14}$. Según J. Ratzinger, Jesús, en el Evangelio auténtico, hablando del Reino de Dios, anuncia simplemente a Dios; es decir, al Dios vivo

la misión que podemos llamar 'antropocéntricas', en el sentido reductivo del término, al estar centradas en torno a las necesidades terrenas del hombre. En esta perspectiva el Reino tiende a convertirse en una realidad plenamente humana y secularizada, en la que sólo cuentan los programas y luchas por la liberación socioeconómica, política y también cultural, pero con unos horizontes cerrados a lo trascendente. Aun no negando que también a ese nivel haya valores por promover, sin embargo tal concepción se reduce a los confines de un reino del hombre, amputado en sus dimensiones auténticas y profundas, y se traduce fácilmente en una de las ideologías que miran a un progreso meramente terreno. El Reino de Dios, en cambio, 'no es de este mundo, no es de aquí' (Jn 18, 36). Se dan además determinadas concepciones que, intencionadamente, ponen el acento sobre el Reino y se presentan como 'reinocéntricas', las cuales dan relieve a la imagen de una Iglesia que no piensa en sí misma, sino que se dedica a testimoniar y servir al Reino. Es una 'Iglesia para los demás', - se dice - como 'Cristo es el hombre para los demás'. Se describe el cometido de la Iglesia, como si debiera proceder en una doble dirección; por un lado, promoviendo los llamados 'valores del Reino', cuales son la paz, la justicia, la libertad, la fraternidad; por otro, favoreciendo el diálogo entre los pueblos, las culturas, las religiones, para que, enriqueciéndose mutuamente, ayuden al mundo a renovarse y a caminar cada vez más hacia el Reino. Junto a unos aspectos positivos, estas concepciones manifiestan a menudo otros negativos. Ante todo, dejan en silencio a Cristo: el Reino, del que hablan, se basa en un 'teocentrismo', porque Cristo - dicen - no puede ser comprendido por quien no profesa la fe cristiana, mientras que pueblos, culturas y religiones diversas pueden coincidir en la única realidad divina, cualquiera que sea su nombre. Por el mismo motivo, conceden privilegio al misterio de la creación, que se refleja en la diversidad de culturas y creencias, pero no dicen nada sobre el misterio de la redención. Además el Reino, tal como lo entienden, termina por marginar o menospreciar a la Iglesia, como reacción a un supuesto 'eclesiocentrismo' del pasado y porque consideran a la Iglesia misma sólo un signo, por lo demás no exento de ambigüedad".

14. Cfr. ibíd., pp. 80-82. 
que es capaz de actuar en el mundo y en la historia de un modo concreto, y precisamente lo está haciendo ahora. Jesús nos dice: Dios existe y, además, Dios es realmente Dios; es decir, tiene en sus manos los hilos del mundo. El mensaje de Jesús es enteramente teocéntrico, pero su aspecto nuevo y totalmente específico consiste en que nos dice: Dios actúa ahora; ésta es la hora en que Dios, de una manera que supera cualquier modalidad precedente, se manifiesta soberanamente en la historia como su verdadero Señor, como el Dios vivo ${ }^{15}$.

Seguramente este planteamiento papal puede satisfacer una necesidad espiritual de los hombres y mujeres de las sociedades occidentales modernas, que andan en búsqueda de un sentido existencial, que creen poder encontrar en "lo divino". Pero deberíamos procurar no hacer de Dios un funcionario del sentido $^{16}$. Es decir, la Iglesia no debiera convertir a Dios en el "remedio espiritual" de unos hombres y mujeres, cuyo malestar es precisamente fruto de una cultura -narcisista, egocéntrica, desesperadamente centrada en la felicidad propia y ciega a la realidad del "otro que sufre" — alejada casi por completo del Dios del Reino. Dios, si acaso, está esperando una conversión que suponga una ruptura radical con la expectativa espiritual de los hombres y mujeres de nuestras sociedades. Dios no está ahí para consolar el vacío existencial derivado precisamente de la renuncia a esa conversión. No deberíamos olvidar que Dios no se revela para llenar el vacío existencial de los hombres y las mujeres occidentales de hoy, sino para comunicarse a todos los hombres - también ciertamente a los hombres y mujeres de las sociedades ricas - como Dios-Amor y mostrar a Jesús de Nazaret como "el Camino, la Verdad y la Vida". Desde este punto de vista, Dios sí es Fuente de sentido. Pero este profundo sentido existencial sólo puede ser experimentado si permitimos que el encuentro con Dios sea lo que efectivamente es: un proceso de descentramiento y de liberación de uno mismo para salir

15. Cfr. ibíd., p. 83.

16. Como ha escrito A. Gesché, "el sentido puede existir, puede ser reconocido y vivido, sin que debamos recurrir necesariamente a Dios, bien sea porque provenga de las mismas cosas de la vida, bien sea porque nosotros lo creemos e introduzcamos en el mundo. Corremos un gran riesgo de instrumentalizar a Dios, el riesgo de convertirle en algo que nos sea útil, de ponerle al servicio del sentido o, quizás, a remolque suyo. Afirmar sin más que Dios es el sentido del sentido implica despreciar la consistencia del sentido. No conviene 'acaparar el cielo' (Sal 72,9a). Cuando existe y está ahí, el sentido posee su autonomía y no tiene necesidad de la sanción de Dios para revelarse como valioso. Dios no es el sentido de las cosas, como si todo lo que se pudiera decir del sentido se hallara sólo en Dios. Pero el sentido tampoco es Dios, como si la búsqueda del sentido equivaliera a la búsqueda de Dios. El sentido no sustituye a Dios y Dios tampoco sustituye al sentido. En un caso y en otro se perjudicaría al sentido, corriendo el riesgo de alienarlo, y se perjudicaría a Dios, reduciéndole a una función. Al mismo tiempo, y en ambos casos, se dañaría al hombre". Cfr. El sentido, Sígueme, Salamanca, 2004, p. 19. 
al encuentro del otro que en primera instancia es aquél en quien el proyecto de Dios se ve negado, esto es, el pobre, la víctima, el marginado, el atropellado y aplastado por las estructuras de nuestra sociedad.

Pero lo que más preocupa de la reflexión del papa-teólogo no es el peligro de hacer un uso funcional de Dios como consuelo de un sin-sentido que procede precisamente de la ceguera a su Amor y a las exigentes consecuencias para nuestra vida concreta, que de este Amor se derivan. Con independencia de que su generalización haga justicia o no a las teologías que él llama reinocéntricas, la visión de J. Ratzinger corre el riesgo de hacer desaparecer el Reino, anunciado por Jesús de Nazaret, tras su idea de Dios o su cristología. Pensamos que su reflexión deja fuera dos elementos totalmente claves del significado que el reino de Dios tuvo para Jesús: la opción preferencial de Dios por los pobres y su beligerancia con los ídolos y los poderes satánicos. Sin ellos se simplifica la complejidad del Reino anunciado por Jesús de Nazaret. Cordial y fraternalmente quisiera hacer un par de observaciones.

Primera. El Dios del reino efectivamente existe, como nos recuerda Benedicto XVI, y adviene como un Dios vivo actuando de un modo concreto en el mundo y en la historia, es decir, haciendo posible lo imposible: la fraternidad universal entre los seres humanos. Pero, como la realidad del mundo es asimétrica, es decir, en él hay pobres porque hay ricos, hambrientos porque hay satisfechos, etc., la presencia actuante divina revela concretamente su identidad paterna como la de un Dios parcial, que se acerca como Evangelio para los pobres ( $c f r$. Lc 4, 18-19) ${ }^{17}$. Jesús percibe a Dios como un Dios que actúa a favor de los pobres; un Dios cuya "salvación está destinada únicamente a los pobres" Jesús convierte parcialmente esta Buena Nueva en realidades históricas buenas a través de la autoridad de su anuncio, de su "forma vitae" y de sus obras poderosas en favor de los hambrientos, los afligidos, los perseguidos, los pecadores, los "más pequeños" y "los sencillos". Los pobres involuntarios se convierten así en sacramento de la salvación universal de Dios (cfr. Mt 25, 31-46). Todos los

17. En los últimos años se ha debatido tanto sobre la identidad de los pobres del Evangelio que merece la pena recordar la descripción que de ellos hace un clásico de la exégesis postbultmaniana. J. Jeremias caracteriza a los pobres con un doble aspecto: (A) Pobres son los pecadores (personas de mala conducta y profesiones que se tienen por viles, como los pastores), los publicanos y las rameras (Mc 2, 16; Mt 11, 19; 21, 32; Lc 15, 1) y "los pequeños" (Mc 9, 42; Mt 10, 42; 18, 10.14), "los más pequeños" (Mt 25, 40.45) o "los sencillos" (Mt 11, 25): a todos ellos su ignorancia religiosa y su comportamiento moral les cerraba la puerta de acceso a la salvación. (B) Pobres, en el contexto de Is 61,1 , son los que sufren bajo el peso de alguna necesidad básica (Lc 6, 20-21; Mt 25, 35 ss), los que son realmente pobres, hambrientos, afligidos o perseguidos, es decir, los oprimidos que no se pueden defender. Cfr. Teología del Nuevo Testamento, Vol. I, Sígueme, Salamanca, 1974, pp. 134-138.

18. Cfr. ibid., p. 142. 
seres humanos estamos llamados a la salvación de Dios, pero ésta irrumpe ayer y hoy en el territorio de los pobres. La unidad de la vida, la muerte y la resurrección de Jesús genera una alianza entre los pobres concretos de este mundo y la salvación de Dios, que ya nunca más podremos desligar. Esta es la novedad jesuánica de la historia de Dios con nosotros. Quienes hayamos hecho nuestro el Evangelio de los pobres de Aquel a quien Dios resucitó compartiremos también su resurrección.

Segunda. Además el Dios del Reino adviene a una historia en la que las fuerzas negativas de la creación, los dinamismos diabólicos representados simbólicamente por el Maligno, tienen poder. "Satanás" es el símbolo del Mal (con mayúscula), encarna la perversión del poder que afecta no solo a los individuos, sino también a las instituciones. Alguien ha dicho que "Satanás" es el espíritu del "sistema de dominación" que abarca el mundo entero. Nosotros necesitamos del lenguaje simbólico del Maligno para seguir recordando la amenaza de lo terrible y de lo bestial. "La perversión del poder, las formas demoníacas de ejercerlo, siguen atormentando nuestro mundo. El mal no es la mera ausencia de bien en el mejor de los mundos posibles. Funciona como si fuera un agente personal; es astuto, inteligente, poderoso, seductor. Todo ser humano se topa en algún momento de su vida con su brutalidad. Tras el sufrimiento de los inocentes casi siempre puede percibirse la sombra de una institución humana que ha abandonado el puesto asignado por Dios al servicio del bien común. El Mal es ese poder oscuro que exige ser servido en lugar de servir. Es un cáncer, células que olvidan su función y crecen sin control absorbiendo recursos y destruyendo la vida. Es un desquiciamiento del poder de las personas y las instituciones, una locura"19.

La irrupción soberana del Reinado de Dios en la historia supone contradicción y conflicto con la realidad presente. "Al 'reino' - como J. Sobrino ha enfatizado tantas veces - se le opone el 'antirreino', y al 'Dios de vida' se le oponen las 'divinidades de muerte". Las acciones de Jesús, sus milagros y curaciones, constituyeron auténticas interrupciones del circuito del mal que avasalla la vida de los hombres y muy singularmente de los pobres y de los débiles. En Jesús de Nazaret el Dios del Reino efectivamente actúa y manifiesta su soberanía, pero no lo hace de manera idealista, sino en su lucha contra el Maligno y contra los ídolos de muerte, representados por Mamón. Entre el Dios del Reino y Mamón (cfr. Mt 6, 24) existe una antinomia irreconciliable. Todo el que está aliado con Mamón está excluido de la familiaridad con el Dios del Reino porque nadie puede al mismo tiempo servir a dos señores. La antinomia Abba-Mamón, como ha explicado A. Pieris, se actualiza históricamente por medio de la alianza de Dios con los pobres o de la parcialidad de Dios por los oprimidos. El Padre de

19. A. de Mingo Kaminouchi, Símbolos de Salvación. Redención, victoria, sacrificio, Sígueme, Salamanca 2007, p. 60. 
Reino asume la lucha de los pobres contra los ídolos de muerte como propia, de modo que se convierte en la lucha divina por la vida de los pobres, la lucha emprendida por el Dios del reino contra los orgullosos, los poderosos y los ricos (cfr. Lc 1, 51-53). Los seguidores de Jesús habrán de ser repudiadores de Mamón o "pobres voluntarios" y los repudiadores de Mamón serán constituidos seguidores de Jesús o "pobres evangélicos". Los mártires constituyen y actualizan de manera eminente este seguimiento porque cargaron jesuánicamente con la dimensión apostólica o misionera de su pobreza voluntaria ${ }^{20}$.

Me pregunto si el déficit de la propuesta de Ratzinger no será consecuencia de aquella codificación eclesiológica del discurso sobre Dios, que K. Rahner criticó en el pasado y que J. B. Metz ha vuelto a poner en el candelero del debate teológico. Pero sí nos atrevemos a afirmar que resulta harto difícil que la Iglesia actual no busque consciente o inconscientemente ganar primordialmente poder social, cultural y eventualmente político con los asuntos relacionados con Dios. Es lo que busca el tradicionalismo católico y espera el neoconservadurismo político en épocas de crisis global. La Iglesia y singularmente quienes mayor representatividad institucional tienen en ella deberían tomar en consideración la autoridad y la competencia de "los otros" (los pobres) y de las otras visiones religiosas a la hora de hablar de Dios. La Iglesia actual vive el riesgo de hacer de Dios una caricatura del miedo en que está estabilizada y que recorre su cuerpo social. La testificación del Dios Vivo tiene ante sí una serie de desafíos: combatir la rampante desesperación eclesial respecto del hombre moderno; impedir que el miedo eclesial al contacto con el mundo moderno degenere en mentalidad sectaria; resistir la tendencia a la guetización y la proclividad al fundamentalismo y a la creciente renuencia a vivir nuevas experiencias e incorporarlas a la autocomprensión de la Iglesia a través de un proceso de dolorosa y crítica asimilación; renunciar al lenguaje exacerbado al estilo zelota y a la militancia reacia a alcanzar un consenso en las controversias intraeclesiales; rechazar la confusión de la eclesialidad con un zelotismo ayuno de alegría y humor; denunciar la propagación de una excesiva exigencia de fidelidad o de los recelos exagerados en la vida eclesial; rehabilitar el deseo de relacionarse sólo con personas que comparten la propia manera de pensar; sortear el peligro de un aislamiento artificial del lenguaje del anuncio, que así se convierte en un puro lenguaje de iniciados, con una semántica típica de las sectas, etc. Hoy necesitamos sensibilidad evangélica y la confianza de la fe para mediar entre la amplitud de Dios y la estrechez de la Iglesia ${ }^{21}$.

20. Cfr. A. Pieris, El Reino de Dios para los pobres de Dios. Retorno a la fórmula de Jesús, Mensajero, Bilbao, 2006, pp. 65-79.

21. Cfr. J. B. Metz, Memoria passionis, óp. cit., pp. 119-120. 


\section{La contribución de un cristianismo liberador a un presente incierto}

Los seres humanos estamos habitados por un anhelo indefinible de plenitud, que buscamos satisfacer permanentemente y solamente paladeamos en forma fragmentaria y siempre amenazada en nuestra historia. Esta nostalgia de plenitud utópica de lo humano o de perfección escatológica solo podemos expresarla adecuadamente en un lenguaje simbólico, que desborde el carácter siempre limitativo y empobrecedor de cualquier intento humano de descripción o definición.

La tradición judeo/cristiana da cuenta de una Promesa de Dios, que pretende dar respuesta a ese deseo inalcanzable del corazón humano. Esta visión fantástica divina ha sido recogida en tres grandes metáforas bíblicas, que sugieren el horizonte de lo que la humanidad desea y está llamada a llegar a ser. (a) El Reino de Dios evoca la salvación definitiva o liberación radical de la humanidad hasta convertirse en una sociedad de hermanos y hermanas, en una comunidad viva en la que ya no existen relaciones amo-siervo, pobres-ricos, donde el dolor y las lágrimas desaparecen en el olvido. (b) La resurrección de la carne alude a la salvación completa y a la felicidad del individuo dentro de la comunidad perfecta, esto es, de la persona humana incluyendo su corporeidad. Y finalmente, (c) el nuevo cielo y la nueva tierra sugiere la consumación del ambiente ecológico que los seres humanos necesitamos para vivir. Estas alegorías orientan la mirada y la acción de los cristianos en el mundo ${ }^{22}$. Su potencial simbólico evoca un horizonte determinado de plenitud humana: una sociedad mejor para todos los hombres y mujeres, especialmente para los pobres y marginados, una salud integral para los individuos y un entorno natural humano; provoca ilusiones y deseos renovados de construir caminos hacia esa plenitud; y además posee la capacidad de convocar, juntamente con los cristianos, a otros hombres y mujeres de diferentes tradiciones culturales y religiosas en la misma dirección y en el mismo camino.

El cristianismo liberador no tiene soluciones para salir de la barbarie y la incertidumbre de nuestro tiempo, pero puede contribuir a su búsqueda y puesta en práctica de los caminos que hagan avanzar en la dirección que conduzca hasta estas soluciones. Para concluir ofrecemos algunas pistas de cristianismo liberador en esta hora histórica.

6.1. Encontrar y mostrar las señales indicadoras de la vigencia de la Promesa de Dios, que ayuden a superar el estado de perplejidad producido por la ideología de la inevitabilidad ( $c f r$. Mt 16, 1-4)

La esperanza mesiánica del cristianismo no evita la sensación de despiste y desvanecimiento que produce la experiencia de la inevitabilidad de lo que ocu-

22. Cfr. E. Schillebeeckx, Jesús en nuestra cultura, Sígueme, Salamanca, 1987, pp. 43-44. 
rre y la persistencia de las injusticias estructurales. Pero se convierte en factor permanente de superación del estado de perplejidad en cuanto que capacita para descubrir las posibilidades todavía inéditas, pero ya viables que el momento histórico encierra para el presente de la humanidad.

Esta perspectiva le dota de sabiduría para identificar las señales de Vida del Crucificado en los "corredores de la muerte" de nuestro mundo. Y capacita para el mayor descubrimiento: en las grietas de este sistema de muerte hay signos de vida; en este inmenso mar lleno de náufragos hay gente que se las ingenia y se organiza para navegar; en pleno ojo del huracán ya se avistan "islas de esperanza" hacia donde dirigir el rumbo; en el interior cautiverio surgen "zonas liberadas"; en nuestras sociedades de siervos se inventan redes de libertad; en las barriadas de la periferia de la cultura satisfecha se promueven prácticas alternativas para la aldea global... Todas estas realidades son anticipaciones históricas del Reino de Dios. Toparse con ellas facilita seguir en la brecha sin echar la toalla o quemarse. Ese encuentro renueva energías. Justamente permite seguir apostando, ya en el presente, por un futuro que tiene toda la fragilidad de lo que aún no existe y de lo que no es demostrable ni manipulable. Ese encuentro nos permite seguir esperando la llegada de un dueño que siempre se retrasa; nos impulsa a negarnos a dejar a nadie por imposible; aguardar con una confianza terca y activa de que en uno mismo y en los otros sigue actuando la semilla del Reino.

Por cierto que esta capacidad del cristianismo para detectar señales del Reino en medio de las ambigüedades de nuestro presente debería empapar nuestra concepción de la Iglesia de arriba abajo. Y en esta tarea debería "recibir" el magisterio de los mártires auténticos expertos de Dios en avizorar las señales de su Reino. La Iglesia debería dejar de ser "el recinto" donde el Espíritu se manifiesta de manera exclusiva y donde, en consecuencia, es administrado burocráticamente, y convertirse en "radar" que detecta y señala aquellas realidades de nuestro mundo donde el Espíritu se está manifestando, muchas veces sin que sus propios protagonistas sean muy conscientes de ello. De una eclesiología que concibe la Iglesia como una ciudadela amurallada — la Ciudad de Dios- encerrada ante el mundo, protegiéndose de él, cuando no enfrentándose con él, deberíamos pasar, como explicara pedagógicamente L. Boff, a la eclesiología como "dedo que señala" el paso de Dios por la historia.

\subsection{Facilitar voz y salida a las víctimas y los excedentes humanos del siste- ma ( $c f r$. Lc 4, 16-22)}

El cristianismo liberador evangeliza según el espíritu de la sinagoga de $\mathrm{Na}-$ zaret. Jesús no explica la promesa mesiánica de Isaías, sino que con su presencia activa anuncia su cumplimiento: los ciegos ven, los cojos andan y el evangelio se anuncia a los pobres. El cristianismo liberador contribuye a la construcción de un nuevo proyecto cultural de solidaridad con los pobres, que, como proclamara 
I. Ellacuría, sustituya la civilización del capital por la civilización de la pobreza. Los mártires se encargaron y cargaron con ese proyecto, expresión histórica de la alianza de Dios con los pobres.

Los tiempos que corren enfrentan al sistema democrático con el reto de la superación de una cultura colonizada por la sensibilidad tecno-económica. La reconstrucción de un proyecto cultural solidario capaz de orientar y de señalar prioridades al quehacer político se ha convertido en el gran desafío para detener la oleada neoliberal que, entre otras cosas, ha puesto en circulación el mito del colapso de todas las utopías. La aportación del cristianismo a esta búsqueda puede ser importante. La fe necesita de las mediaciones sociopolíticas para cumplir con su misión: salvar hombres y mujeres. Y nuestro mundo está necesitado de esfuerzos masivos y eficaces de salvación. Pero salvar - de la miseria, del hambre, de la muerte injusta, etc. - se ha hecho extremadamente difícil en la hora presente. El cristianismo, desde el instinto evangélico, aporta criterios que orientan los objetivos políticos y jerarquizan sus prioridades desde los intereses de los más desfavorecidos.

En cierto sentido, el momento histórico presente está atenazado en una absurda paradoja que enfrenta las capacidades objetivas de liberación con el horizonte cultural que debería ponerlas en marcha. Como bien sabemos, la utopía de la emancipación universal fue vehiculada, durante los dos últimos siglos, por medio de las ideologías de origen ilustrado: socialismos de varias especies, a los que siguieron movimientos sociales dedicados a la causa de la paz, de la ecología, de la solidaridad y el desarrollo del los pueblos del Sur o del fin del orden patriarcal. La postmodernidad decretó el fin de las utopías de la emancipación, por defecto irreversible de fábrica de la bóveda que sostenía todo el edificio utópico: la razón moderna. Sin embargo, estas utopías eran las depositarias de las esperanzas de las víctimas de las distintas estructuras de opresión política y cultural y de explotación económica que, como un "molino satánico" — por seguir la metáfora que K. Polanyi utilizara para definir el sistema de mercado autorregulado, en La gran transformación-, reinan en nuestras sociedades, ya sea a escala nacional o a escala internacional. Decretando el fin de la razón moderna y de las ideologías de la emancipación que reposaban en ella, parecía que las víctimas de nuestro mundo se quedaban, de la noche a la mañana, sin derecho a esperar una vida mejor. ¿Quién se iba a hacer cargo, de ahora en adelante, de la causa de la justicia?

Al mismo tiempo, el siglo XXI es el primer siglo de la historia en el cual se dan las condiciones objetivas para hacer realidad los derechos humanos básicos para todas las personas y en todos los rincones del planeta. Por primera vez en la historia, la humanidad cuenta con los medios técnicos, económicos y políticos para construir una suerte de Welfare global. El gran reto del siglo XXI es pasar del Welfare State al Welfare World. Por primera vez en la historia, contamos con 
los medios técnicos, económicos y políticos para erradicar la pobreza extrema ${ }^{23}$. Los Objetivos del Milenio no son un horizonte ideal imposible de cumplir, sino una tarea perfectamente al alcance del siglo. Y la erradicación de la pobreza extrema es el primero de los peldaños de la escalera de liberación integral de todos los hombres y mujeres, que nos ha encomendado ascender el Dios de Jesús. La paradoja, por lo tanto, está clara: hay un desencaje entre las condiciones técnicas y sociopolíticas de la humanidad, y el proyecto colectivo que un contexto cultural peinado en su momento por la postmodernidad y marcado todavía hoy por décadas de hegemonía neoliberal no permite construir. Estamos en condiciones - técnicas, económicas y políticas - de dar a las víctimas una salida a su postración, pero están desaparecidas aquellas ideologías que pretendían revertir de una vez por todas la situación de los desheredados de la tierra.

Nuestra historia reciente explica sobradamente esta paradoja. Las ideologías de la emancipación cometieron dos pecados que justifican su colapso. Su fe en la razón les condujo a un optimismo histórico, un mesianismo secular, que les hizo creer que la salvación podía ser completa en la tierra y que dependía, por entero, de las solas fuerzas humanas. Pero los cristianos sabemos que el pecado - también el estructural - no puede ser derrotado con el simple auxilio de la razón y de la voluntad. En segundo lugar, sus realizaciones históricas fueron, en muchas ocasiones, la negación de la promesa de la que eran portadoras. Pero, en cualquier caso, no es análisis de las razones que explican el entierro de las ideologías de la emancipación, en la forma moderno-ilustrada que tomaron a lo largo del siglo XX, sino la toma de conciencia de la actual paradoja. Ante esta situación, la responsabilidad del cristianismo se hace todavía más evidente: el cristianismo liberador puede revivificar el relato de la emancipación, pero hacerlo desde otras bases antropológicas y desde otra filosofía de la historia; puede rehabilitar todo aquello que en las ideologías de la emancipación modernas sigue teniendo valor; está en mejores condiciones que nadie para responder las objeciones postmodernas a las utopías históricas.

Si la humanidad puede hoy garantizar la dignidad de todos sus miembros, que se concreta en la realización efectiva de todos los derechos humanos básicos, el cristianismo no puede inhibirse de tal reto sin faltar a su vocación a la vez histórica y espiritual. Si los medios técnicos, políticos y económicos están disponibles, los cristianos tienen que contribuir a revertir las condiciones culturales que impiden que este proceso de liberación masiva se ponga en marcha. La Iglesia tiene motivos sobrados para sumarse a este combate cultural que activa procesos de solidaridad conducentes a reformar las estructuras económicas, polí-

23. Sobre esta cuestión pueden leerse textos de referencia recientes como J. Sachs, El fin de la pobreza, Taurus, Madrid, 2004; y J. Stiglitz, Cómo hacer que funcione la globalización, Taurus, Madrid, 2006, entre muchos otros posibles. 
ticas y sociales, nacionales e internacionales, que obstaculizan la utopía posible de la libertad real para todos.

A veces tengo la impresión de que bastantes de los actuales posicionamientos eclesiales viven bajo el hechizo de la desmemoria. El tiempo de los mártires ha pasado. Las cosas han cambiado. Estamos en otro momento. Parece como si sus causas, sus sueños, sus esperanzas y sus anhelos fueran algo así como residuos arqueológicos de épocas pasadas o bienes culturales que hay que guardar en un museo. Yo me niego a creerlo. No me lo impide la nostalgia de tiempos pasados mejores, sino el instinto cristiano. En la medida que se dé este olvido me parece un grave error pastoral de la Iglesia, de las Iglesias locales, de las comunidades y congregaciones religiosas. La memoria de los mártires y la remembranza de su sufrimiento y del que dio sentido a sus vidas y a su muerte martirial, el del pueblo crucificado, resultan imprescindibles para actualizar a la Iglesia como comunidad de comunidades de memoria en este tiempo de amnesia cultural y social. Ese recuerdo permanente impide que privemos de significado existencial e histórico a todo lo desaparecido e irrevocablemente pasado y excluyamos la añoranza de nuestros doctos saberes. Esa memoria contribuye a la actualización de la "memoria passionis et resurrectionis" de Jesús de Nazaret. Sin su memoria y sin su esperanza el cristianismo pierde su aguijón apocalíptico y sin él se diluye en una religión para las festividades burguesas o para el consuelo sin futuro de los pobres ${ }^{24}$.

\subsection{Contagiar la energía de esa esperanza que permite vivir con la cabeza levantada en medio del peligro ( $c f r$. Lc 21,28$)$ y caminar erguidos con el peso de los agobios históricos ( $c f r$. Mt 11, 28-30)}

El radical desencantamiento de los ciudadanos de las llamadas sociedades avanzadas produce la crisis de la voluntad de vivir. Demasiados hombres y mujeres no encuentran hoy motivos suficientemente estimulantes para emplearse a fondo en la búsqueda responsable y continuada de salidas a la barbarie. Se nos advierte que o damos un cambio de sentido en nuestra marcha o se acaba la humanidad. Si queremos sobrevivir, el viraje hemos de darlo hacia un sistema que ponga el respeto a la dignidad humana y a la naturaleza por encima del lucro inmediato y del modelo de calidad de vida de la cultura satisfecha del Norte. Pero carecemos colectivamente de una fuerza real capaz de poner en práctica algunas de las recetas que hemos imaginado para salir del marasmo en el que nos encontramos. Solamente la constatación de que aquellos desafíos se han convertido en amenaza de catástrofe absoluta y global para la humanidad, tiene la virtualidad de liberar alguna energía para poner manos a la obra, aunque sea de tan baja intensidad como el provecho y el amor propios o el egoísmo individual.

24. Cfr. J. B. Metz, Memoria passionis, óp. cit., pp. 127-158. 
En estas circunstancias el cristianismo aporta capacidad para vivir erguido en medio de las dificultades. El Espíritu de la Promesa le ha dotado con la destreza práctica de rehacer el vínculo entre felicidad y salvación. La esperanza cristiana habilita hombres y mujeres que airean el secreto sublime de la bienaventuranza evangélica: a la felicidad no se accede por la vía rápida y directa de la propia autoafirmación, sino por el rodeo de la solicitud por los pobres, los que lloran, los que padecen hambre... Sus prácticas pregonan que vivir inteligentemente es vivir solidariamente y que la creatividad de la vida humana alcanza su punto culminante, cuando se las ingenia para multiplicar panes y peces por los caminos del mundo. Su proximidad hace sentir el atractivo, no exento de peligros, de unas historias que poseen un enorme y extraño potencial de contagio y seducción. Semejantes vidas tan desvalidamente humanas, tan machadianamente ligeras de equipaje, contagian el deseo y la ilusión de proseguir como vida buena la gozosamente compartida con la causa de los pobres. Esas historias, tan desconcertantes e insólitas, poseen el poder desconocido de conseguir que en otras broten oportunidades nuevas e inéditas de felicidad, hacen saltar la chispa que alumbra fuentes olvidadas de gozo y hacen sonar la melodía alegre que despierta una nueva conciencia de sí; y permiten que se descubra ese yacimiento ignorado que promete algo más grande y más noble de lo jamás pensado: ser perfectos y misericordiosos como el Padre celestial es perfecto y misericordioso (cfr. Mt 5, 48; Lc 6, 36).

Los mártires han sido testigos privilegiados de ese vínculo entre salvación y felicidad. Por ello son hoy teofanías del rostro de Dios en medio de las oscuridades y de la injusticia. De su memoria brota una energía que nos permite mantenernos en una refriega que fue la suya y es la de Dios: la de no vender por un plato de lentejas ni lo santo, ni la historia de sufrimiento del mundo.

¡En memoria de ellos! 